\title{
Pre-service mathematics teachers' nature of understanding of the tangent function
}

\author{
Priestly Malambo \\ Department of Mathematics and Science Education, University of Zambia, Zambia \\ Corresponding author: priestly.malambo@unza.zm
}

\begin{abstract}
ARTICLE INFO
Article history:

Received: 2 April 2020

Revised: 4 May 2020

Accepted: 6 May 2020

Published online: 13 May

2020

Published regularly: June 2020

Keywords:

Pre-service mathematics

teachers, graphical

representation, translation,

compartmentalization,

advanced mathematics,

tangent function

ABSTRACT

Mathematics teachers' ability to translate and make connections between representations of functions requires investigation. Consequently, this qualitative case study article focuses on pre-service mathematics teachers' nature of understanding of the tangent function; a function bearing unique characteristics compared with the sine and cosine functions. Twenty-two finalist pre-service teachers were conveniently selected and assessed concerning the ability to translate a tangent function to the graphical representation. Likewise, participants' abilities to correctly explain this function and provide appropriate justifications for espoused perspectives were investigated. Although the teachers learned higher mathematics, their assessment was school mathematicsbased. Descriptive analyses showed that only one teacher (5\%) accurately completed the task. Eleven teachers (50\%) did not provide graphs; suggesting a lack of knowledge required to change representation. Ten (45\%) drew flawed graphs depicting a lack of understanding of discontinuity of the tangent function at certain angles and the role of a domain. Essentially, these demonstrated mere memorization of the appearance of the tangent graph. A purposive subsample of size six then participated in exploratory semi-structured interviews. The interviews allowed participants to elucidate their answers to the initial task. Content analysis of the transcripts corroborated the earlier finding as the interviewees could not coherently explain the tangent function, and failed to justify their reasoning. The teachers demonstrated a superficial understanding despite having studied advanced mathematics. This reinforces the view that studying advanced mathematics does not assure a relational understanding of school mathematics. Therefore, it is necessary for trainee teachers to explore school mathematics.
\end{abstract}

(C)2020 Universitas Muhammadiyah Surakarta

\section{Introduction}

An aspiration that Mathematics Teacher Education Programs should have relates to student teachers' acquisition of in-depth understanding of mathematics concepts and skills which could facilitate effective teaching of mathematics at the school level. The extent to which this becomes a reality is dependent on several considerations such as how teachers are trained in university. While it may not be disputed that teachers of mathematics require an understanding of mathematics subject matter, there is normally a lack of

To cite this article:

Malambo, P. (2020). Pre-service mathematics teachers' nature of understanding of the tangent function. JRAMathEdu (Journal of Research and Advances in Mathematics Education), 5(2), $105-118$. doi:https://doi.org/10.23917/jramathedu.v5i2.10638 
consensus when it comes to the content of the mathematics courses teachers ought to study during training. In this regard, different schools of thought exist. For instance, the author of this article has interacted with mathematics educators who contend that it is sufficient to allow student teachers to study advanced mathematics in universities and that those who want to be teachers of mathematics should thereafter study teaching methods courses after graduation for certification. There is a salient assumption that advanced mathematics inevitably equips prospective teachers with the ability to understand school mathematics concepts. However, a scholarly argument exists that mathematics taught at the school level is unique and not a lower version of the mathematics taught in universities (Bromme, 1994). Some of the scholars who acknowledge that comprehension of higher mathematics can facilitate understanding of the mathematics taught in schools also contend that advanced mathematics is not sufficient for effective teaching (Cooney \& Wiegel, 2003). Moreover, there is research evidence suggesting that mathematics student teachers do have conceptual difficulties with topics which they are expected to teach (Malambo, 2016; Malambo et al., 2019).

One of the school mathematics topics which are receiving attention in mathematics education research is trigonometry (Abdulkadir, 2013; Akkoc, 2008; Malambo et al., 2018; Ogbonnaya \& Mogari, 2014). This topic presents advantages to learners such as improving their ability to reason and represent information in different forms (Abdulkadir, 2013). Besides, trigonometry is useful to the study of calculus and navigation. Among what has been researched on under trigonometry are units of angle measures, and general trigonometric concepts (Abdulkadir, 2013; Akkoc, 2008; Malambo, 2016; Malambo et al., 2018; Ogbonnaya \& Mogari, 2014). Trigonometric concepts have been researched through case study designs that allow for relating of results to other contexts without room for generalization. A dominant finding of those studies though is that student teachers exhibit conceptual difficulties in understanding trigonometric concepts (Abdulkadir, 2013; Akkoc, 2008; Malambo et al., 2018).

In Zambia, trigonometry occupies a central position in the mathematics curriculum designed for secondary school learners and it is taught through to the university level. Notwithstanding, there is scant reported research work concerning Zambian pre-service mathematics teachers' nature of understanding of trigonometry concepts as taught in secondary schools (Malambo, 2016; Malambo et al., 2018). It is this reality which partly motivated the researcher to conduct the large study upon which this article is based. The intention was the assessment of whether or not mathematics trainee teachers' study of advanced courses at university does result in their acquisition of relational understanding (Skemp, 2006) of the mathematics concepts they are expected to teach in secondary schools. The current article reports partial findings of that study and focuses on the nature of understanding by university student teachers of one of the trigonometric functions: the tangent function. An online search of journal articles concerning research literature on trigonometry suggested that there is a general lack of African context studies that have specifically investigated student teachers of mathematics' capacity to exhibit a personal understanding of a basic tangent function (Malambo, 2016). The tangent function is unique when compared to the sine and cosine functions which bear similar characteristics in terms of the period, and extreme values. For example, the tangent function has a period of $180^{\circ}$ and has unlimited values. Furthermore, the tangent function is discontinuous at angles such $90^{\circ}$ and $270^{\circ}$ in the domain $0^{\circ} \leq \theta \leq 360^{\circ}$. It is characteristics like these, together with the appropriate justifications thereof which are expected to be conceptually understood by pre-service mathematics teachers. 
This article augments the view that pre-service mathematics teachers who have studied advanced mathematics in a university may not necessarily have an in-depth understanding of mathematics concepts taught at the school level. Specifically, the article demonstrates that pre-service mathematics teachers who had studied advanced mathematics exhibited understanding which is compartmentalized within representations and concepts (Gerson, 2010) in respect of the basic tangent function. The article enhances our understanding by addressing first and foremost the question: How can student teachers of mathematics' capacity to change representation in the context of the tangent function be described? Secondly, how do the pre-service mathematics teachers explain their understanding of the tangent function? Thirdly, what justifications do pre-service mathematics teachers provide for their reasoning about the tangent function?

\section{Research Methods}

This investigation was a qualitative case study (Merriam, 2009; Creswell, 2012; Creswell, 2014) focusing on the nature of understanding of the tangent function held by mathematics student teachers and was conducted at the University of Zambia (UNZA). This site was considered appropriate as it is accessed by the majority of the citizens of Zambia. Furthermore, UNZA is the largest public institution in Zambia with the longest history of training graduate teachers of mathematics. Twenty-two student teachers who were in the final year of study and majoring in mathematics were conveniently sampled. The sampled student teachers then wrote a mathematics test specifically developed for the study. The students were training as secondary school teachers of mathematics. Furthermore, the student teachers had completed courses in fields such as Algebra, Complex Analysis, Statistics, Real Analysis, and Mathematics Education. Mathematics courses were taught in the School of Natural Sciences, a school whose primary mandate is not to train teachers of mathematics. Thus, the student teachers studied the same mathematics content which future mathematicians study. Mathematics education courses which are centered on methods of teaching mathematics were learned by the students in the Department of Mathematics and Science Education.

What pre-service mathematics teachers know of mathematics concepts and the nature of their understanding may be investigated using relevant categories of teacher knowledge frameworks (Malambo, 2016). Researchers have tackled the issue of teacher knowledge through frameworks (Ball et al., 2008; Nyikahadzoyi, 2013; Shulman, 1986). A critical part of teacher knowledge called content knowledge was conceptualized by Shulman (1986) as subject matter knowledge, curricular knowledge, and pedagogical content knowledge. In a quest to clarify what should consist of necessary teacher knowledge for effective teaching, Ball et al. (2008) developed the mathematical knowledge for teaching (MKT) framework which builds on Shulman's idea of content knowledge. The MKT consists of six knowledge domains: Common Content Knowledge (CCK), Specialized Content Knowledge (SCK), Horizon Content Knowledge (HCK), Knowledge of Content and Teaching (KCT), Knowledge of Content and Students (KCS), Knowledge of Content and Curriculum (KCC). The first three domains relate to what Shulman theorized as subject matter knowledge and the last three are linked to what Shulman conceptualized as pedagogical content knowledge.

The conceptual framework (CF) of the study upon which this article is based was an adaptation from the works of other scholars (Shulman, 1986; Ball et al., 2008; Bair \& Rich, 2011; Steele et al., 2013; Nyikahadzoyi, 2015). The CF was heavily influenced by ideas from the MKT framework. Of course, the MKT has limitations in definitions of its domains, and it is a product of a process involving elementary school teachers (Malambo, 2016). Despite 
the limitations, ideas of the MKT framework resonated with the objectives of the study in the sense that those ideas have relevance to what teachers ought to understand to be effective. Specialized Content Knowledge which is a relevant category for this article was conceptualized as: (i) capacity to represent concepts in different forms, and (ii) aptitude to explain as well as to justify reasoning. Each of these sub-categories was defined by specific descriptors, for example (i) involved presenting information in different forms, determining the accuracy of given representations, working with different notations, and translating between representations. On the other hand, part (ii) was defined by the following descriptors: provision of mathematical explanations for common rules and procedures, recognizing and explaining conceptual differences and relationships, explaining the understanding of concepts (definitions, properties, theorems, and formulas) and justifying rules, algorithms, and use of specific methods.

The test instrument which was administered to the twenty-two pre-service teachers consisted of six open-ended trigonometry questions prepared based on the mathematics curriculum which is taught at secondary school level in Zambia (Ministry of Education, 2013a). Test questions were aligned to the descriptors of sub-categories such as (i) and (ii) above of the study's CF. Applicable descriptors for the component ability to use different representations were used for the task in Figure 1 below.

$$
\text { Sketch the graph of } y=\tan \theta \text { for } 0 \leq \theta \leq 360^{\circ} \text {. }
$$

Figure 1. Administered item

The item in Figure 1 assessed pre-service mathematics teachers' capacity to accurately translate a tangent function from an algebraic representation to a graphical form in a scenario where the domain is specified. Equally, student teachers' aptitudes to use degrees for angles as was the case with the given domain were investigated. The required graph was expected to include accurate and complete labeling of the Cartesian plane. Besides, accurate plotting of the major points such as $\left(0^{\circ}, 0^{\circ}\right)\left(180^{\circ}, 0^{\circ}\right),\left(360^{\circ}, 0^{\circ}\right)$ was required. Furthermore, a clear indication of the angles at which the tangent function is discontinuous was expected. Last, but not least, showing the graphical characteristics of the tangent function between $0^{\circ}$ and $90^{\circ}, 90^{\circ}$ and $180^{\circ}, 180^{\circ}$ and $270^{\circ}, 270^{\circ}$ and $360^{\circ}$ was required. Pre-service mathematics teachers' answers to the item were scored using a rubric based on these considerations and analyzed using descriptive statistics.

Following descriptive analyses of the student teachers' answers to the item, a subsample of six pre-service mathematics teachers were purposively drawn for participation in semi-structured interviews which explored their nature of understanding of the tangent function. The interviewees were also shown the graphs which they had drawn and were asked to elucidate their answers. Interview transcripts were analyzed using descriptors of the component of SCK: Ability to explain and justify reasoning. Specifically, content analysis was employed to analyze the transcripts.

\section{Results and Discussion}

The results presented here are based on the pre-service mathematics teachers' answers to the item in Figure 1 and on the exploratory semi-structured interviews administered to the sub-sample. The task in Figure 1 allowed the participants to demonstrate their understanding through paper and pencil whereas the interviews provided a chance for them to orally explain their answers to the item. 
In respect of Figure 1, eleven pre-service mathematics teachers did not provide graphs. Ten student teachers drew flawed graphs, and only one student-teacher accurately and completely sketched the tangent function in the specified domain. This information is summarized in Figure2.

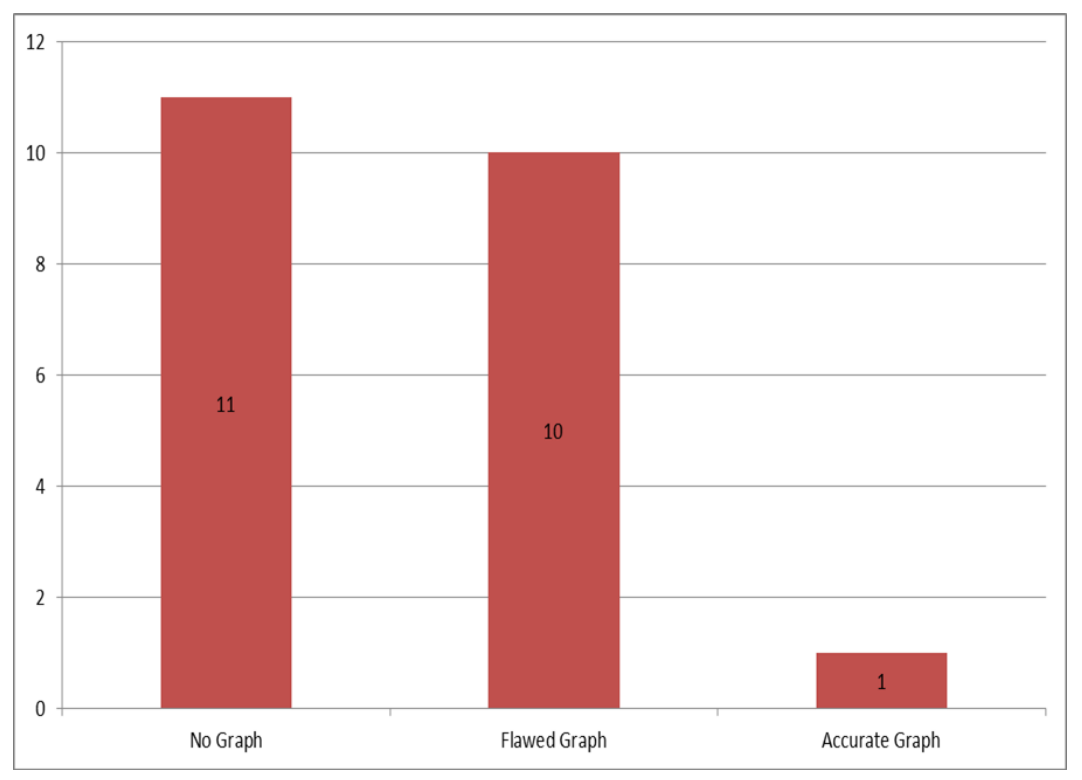

Figure 2. Results of pre-service teachers' responses to the task in Figure 1

Figure 2 indicates that the modal class relates to pre-service mathematics teachers who presented no graphs (50\%). Furthermore, the number of pre-service mathematics teachers who drew flawed graphs (45\%) is almost equal to the number of those who did not draw any graph, and only 5\% of the sample presented an accurate graph. These results demonstrate that majority of the pre-service mathematics teachers (95\%) could not change the representation of a symbolic tangent function to its corresponding graphical representation. In the segment below, three illuminating samples of flawed graphs as drawn by pre-service mathematics teachers are presented as Figures 3, 4, and 5 followed by respective analyses.

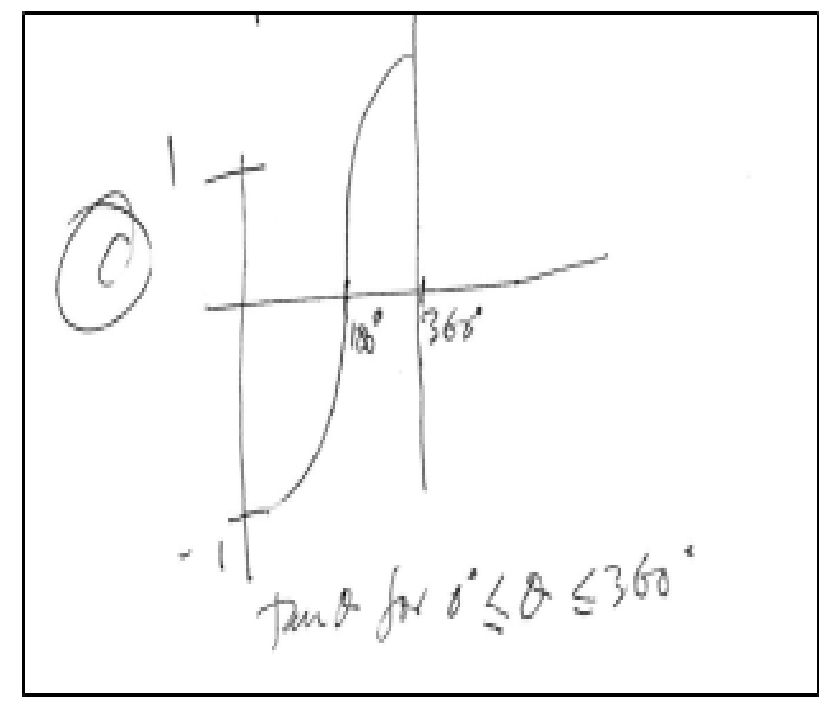

Figure 3. Graph of $y=\tan \theta$ for $0^{\circ} \leq \theta \leq 360^{\circ}$ as drawn by a pre-service teacher 
Figure 3 displays -1 and 1 on the vertical axis which seems to have no basis except to suggest that the pre-service teacher could have been thinking of maximum and minimum values as they relate to the sine and cosine functions. The drawn graph appears to have a minimum value of -1 while its supposed maximum value exceeds 1 . Apart from that, the curve does not meet any of the characteristics of the graph of a tangent function. For example, it is a known fact that the graph of a tangent function has three curve segments in the interval $0^{\circ} \leq \theta \leq 360^{\circ}$. Figure 3 shows only a single curve segment which notwithstanding is incorrect.

Other invalid ideas that come to light upon close examination of Figure 3 relate to scenarios where $\tan 360^{\circ}$ are suggested to have a value greater than zero. Likewise, $\tan 0^{\circ}$ is erroneously suggested to have a value of -1 (although the origin is not clearly labeled it is implied). Furthermore, the values of the tangent function are suggested to all be negative in the interval $0^{\circ} \leq \theta<180^{\circ}$ when in actual sense the function has positive values in the interval $0^{\circ}<\theta<90^{\circ}$, negative values in the interval $90^{\circ}<\theta<180^{\circ}$, and a value of zero at $180^{\circ}$. It should also be taken note that an impression is created that the tangent function is defined at $90^{\circ}$ when the fact is that it is not continuous at that angle. Revealingly too, is an inexplicable vertical axis that was drawn through $360^{\circ}$.

The foregoing is indicative that the pre-service mathematics teacher who presented Figure 3 could not represent the tangent function using a graph. What follows is another sample graph as presented by a pre-service mathematics teacher.

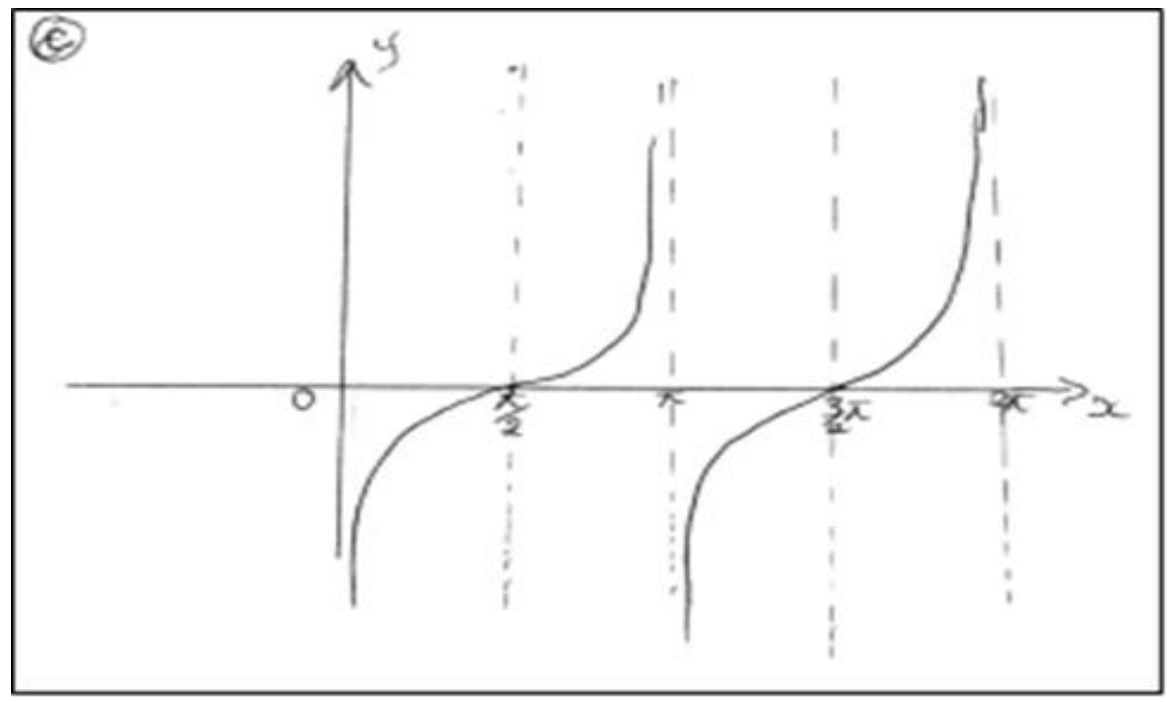

Figure 4. Graph of $y=\tan \theta$ for $0^{\circ} \leq \theta \leq 360^{\circ}$ as drawn by another pre-service teacher

Figure 4 suggests that the student-teacher who presented the sketch had a view that the graph of a tangent function should have its angles expressed in terms of $\pi$. This is because the domain of the function in Figure 1 was expressed in degrees and there was no instruction to convert the unit of measure. Besides, Figure 4 implies that the tangent function is defined at $\frac{\pi}{2}$ and $\frac{3 \pi}{2}$ and that it has a value of zero at these angles. However, what is mathematically correct is that at these angles the function is undefined. This figure also suggests that at $0, \pi$ and $2 \pi$ the tangent function is undefined when the fact is that it is continuous at these angles and has a value of zero. Other incorrect implications of Figure 4 
are that between 0 and $\frac{\pi}{2}$ the tangent function has negative values and that in the interval $\frac{\pi}{2}<\theta<\pi$ the function has positive values. Nevertheless, the correct positions are that between 0 and $\frac{\pi}{2}$ the function has positive values whereas it has negative values in the interval $\frac{\pi}{2}<\theta<\pi$. Furthermore, Figure 4 erroneously suggests that the tangent function has negative values in the interval $\pi<\theta<\frac{3 \pi}{2}$ and positive values in the interval $\frac{3 \pi}{2}<\theta<2 \pi$. The interpretations of Figure 4as highlighted above provide strong confirmation that the mathematics student teachers lacked mathematical knowledge required to accurately translate a symbolic tangent function to a graphical representation. teacher.

Figure 5 is the third sample answer as provided by a pre-service mathematics

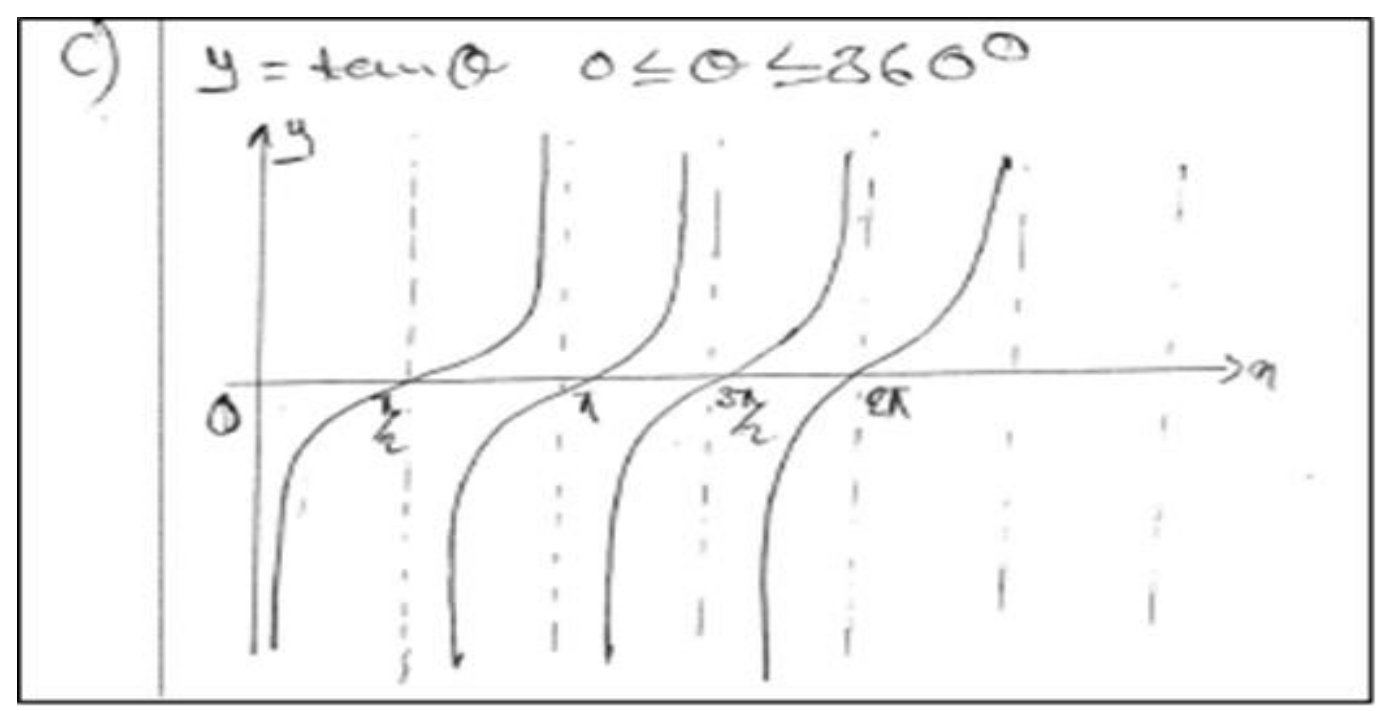

Figure 5. Graph of $y=\tan \theta$ for $0^{\circ} \leq \theta \leq 360^{\circ}$ as drawn by another pre-service teacher

The student who presented Figure 5most likely had an understanding that angles of a graph of a trigonometric function should be expressed in terms of $\pi$. Most revealing too is that the student teacher's graph went beyond $2 \pi$ (an equivalence of the upper limit of the domain $0^{\circ} \leq \theta \leq 360^{\circ}$ ). This points to a lack of understanding of the centrality of a domain when defining a function. Similar to the observations made in Figures 3 and 4, Figure 5 suggests that the tangent function is not defined at zero. This figure also portrays an incorrect view that the tangent function is defined at the angles $\frac{\pi}{2}$ and $\frac{3 \pi}{2}$. Besides, Figure 5 suggests that the values of $\tan \frac{\pi}{2}$ and $\tan \frac{3 \pi}{2}$ is zero when in actual sense the tangent function is undefined at $\frac{\pi}{2}$ and $\frac{3 \pi}{2}$. Other incorrect implications of Figure 5 are that the tangent function has negative values between 0 and $\frac{\pi}{2}$ and that in the interval $\frac{\pi}{2}<\theta<\pi$ the function 
has both positive and negative values. Likewise, Figure 5 portrays the wrong view that the tangent function has both positive and negative values in the interval $\pi<\theta<\frac{3 \pi}{2}$.

The preceding analysis augments the view that the sampled pre-service mathematics teachers had not acquired the necessary knowledge required to change the representation of a symbolic tangent function to the graphical representation. In the subsequent section, synopses of the interview findings are presented.

\section{The idea of the period of a function}

Five of the six interviewees correctly stated that the period of the tangent function is $180^{\circ}$. This was interesting; especially that $95 \%$ of the initial sample could not sketch the graph of the basic tangent function. Nevertheless, the participants' inability to provide comprehensive explanations of what a period of a function entails confirmed that their correct response of $180^{\circ}$ as being the period of a tangent function was a mere reproduction of a fact without understanding. A discussion held with the pre-service teacher denoted $\mathrm{I}_{1}$ who provided Figure 3 reinforce this perspective as shown by the following excerpt:

$\begin{array}{lll}\text { Researcher }_{(R)} & : & \text { Would you explain to me what the term 'period of a function' means } \\ \text { Interviewee }_{1}\left(I_{1}\right) & : & \begin{array}{l}\text { Period of a function is actually the (pauses), it is the period that a particular } \\ \text { function makes, a complete (stammers), a complete turn }\end{array}\end{array}$

The student-teacher was probed for clarification following the perspective that a period is 'a complete turn':

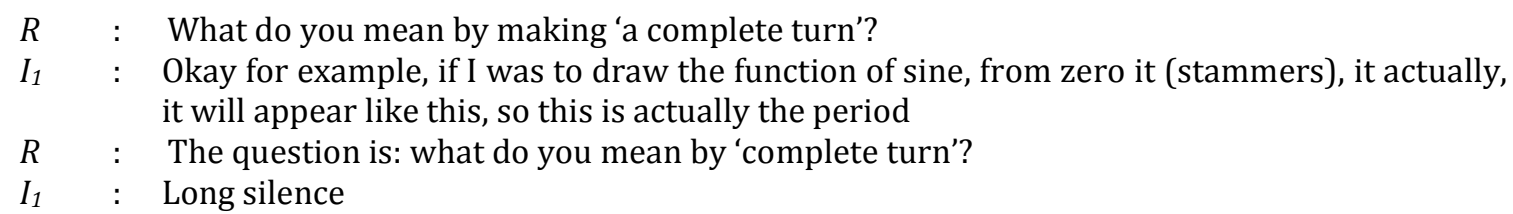

The preceding excerpt shows that the student-teacher could not clarify the meaning of 'complete turn' which conclusively suggests a lack of ability to explain the idea of a period of a function.

\section{Explanations and justifications concerning features of the tangent function}

The pre-service mathematics teachers were interviewed concerning what they knew of the characteristics of the tangent function. Equally, follow up questions were posed to allow the student teachers to explain and justify the graphs they had drawn. The majority of the pre-service teachers demonstrated the inability to coherently explain and justify their purported features of the tangent function. A model example here is the pre-service teacher symbolized by $I_{2}$ and who presented Figure 4 . The ensuing extract represents the discussion held with that respondent:

$R \quad$ : Why do you think [that] the value of $\tan 270^{\circ}$ is zero?

$I_{2} \quad$ : Because when I look at the tan [tangent] curve, it goes; cuts at $\frac{\pi}{2}$. It goes 'asymptotically' at $270^{\circ}$. It just goes if I'm not mistaken; it goes straight it doesn't cut the $x$-axis at $270^{\circ}$ 
The foregoing excerpt epitomizes the teacher's lack of relational understanding. Firstly, the teacher believed that the tangent curve intercepts the vertical axis $\theta=\frac{\pi}{2}$ when in actual sense the function is undefined at the angle $\frac{\pi}{2}$. Secondly, the teacher's declaration that the tangent graph does not cross the horizontal axis $(y=0)$ at $270^{\circ}$ suggests the inability to justify as well as conflicted understanding if considered alongside Figure 4. This figure shows a supposed tangent curve crossing the $x$-axis $(y=0)$ at the angle equivalent to $270^{\circ}$ $\left(\frac{3 \pi}{2}\right)$. The pre-service teacher's knowledge of a strategy to convert angles in degrees to their equivalents expressed in terms of $\pi$ augmented the evidence of lack of understanding of significant features of a tangent function. When shown in Figure 4 and asked to provide clarity, the student-teacher claimed that $\tan 270^{\circ}$ is zero because $270^{\circ}$ lies on the $x$-axis . This explanation was superficial because every other angle of the curve lay on the $x$-axis . Another excerpt which provided insight is given below:

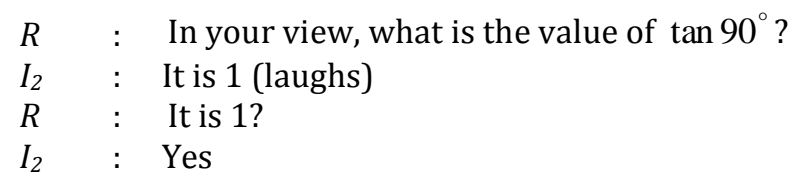

The view that the value of $\tan 90^{\circ}$ is 1 contradicted what was depicted in Figure 4 . In this figure $\tan 90^{\circ}$ was shown to be equal to zero. This conflict validated the pre-service teacher's lack of understanding that the tangent function is undefined at $90^{\circ}$ and at $270^{\circ}$.

A pre-service teacher denoted $I_{3}$ and who presented Figure 5 posited that $\tan 270^{\circ}$ is equal to $\frac{1}{\sqrt{3}}$, but could not give a reason for this flawed point of view. It would appear that the teacher perceived $\tan 270^{\circ}$ to be equal to $\tan 130^{\circ}$. Most likely the student-teacher might have used dimensions from the special triangle containing the special angle $30^{\circ}$ to arrive at the incorrect value of $\tan 270^{\circ}$. Another misconception brought out by pre-service teacher $\mathrm{I}_{3}$ was in the context of the perceived value of $\tan 90^{\circ}$. The excerpt below provides insight:

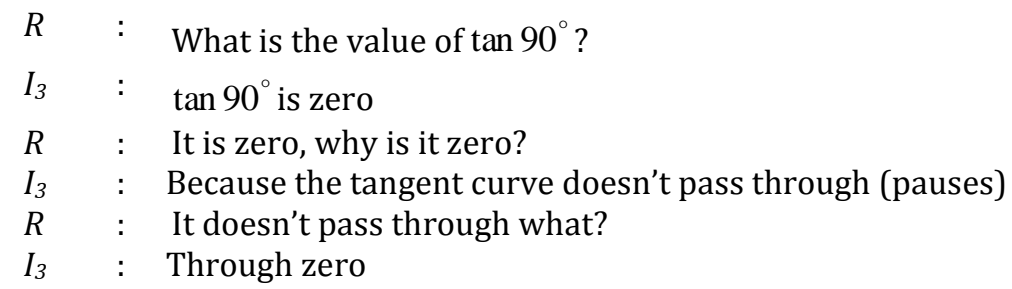

The preceding extract shows corroboration between the student teacher's interview views and Figure 5. For example, the student-teacher consistently claimed that $\tan 90^{\circ}$ has a value of zero. This view is exemplified in Figure 5and amply suggests the student teacher's lack of knowledge that the tangent function is undefined at $90^{\circ}$. A perceived justification by the teacher that $\tan 90^{\circ}$ is equal to zero 'because the tangent curve does not intersect the point $(0,0)$ ' is superficial. While Figure 5 consistently shows that the drawn curve does not 
pass through the origin, that view is incorrect because $\tan 0^{\circ}$ exists and is equal to zero. Moreover, the student-teacher asserted during the interview that $\tan 0^{\circ}$ is equal to zero and this conflicted the earlier supposed justification. It seems that the student-teacher did not understand that having a value of zero for $\tan 0^{\circ}$ implied that the tangent curve intercepts the origin.

The student-teacher also claimed that the tangent function is not defined at $180^{\circ}$, but he could not give any valid justification when requested. This scenario confirmed the student teacher's lack of relational understanding that $\tan 180^{\circ}$ has a value of zero. Amazingly, the student teacher's revelation during the interview was not consistent with the graph drawn. Figure 5 portrays that $\tan 180^{\circ}$ is defined and that it has a value of zero. In this regard, the student-teacher demonstrated a discrepancy in understanding.

\section{The idea of extreme values}

The pre-service teacher who presented Figure 4 confessed a lack of understanding concerning the idea of maximum values in the context of a tangent function. When queried about a minimum value the discussion went as follows:

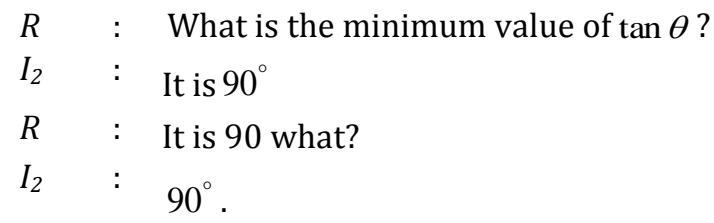

The notion that the minimum value of the tangent function in an unspecified domain is $90^{\circ}$ suggests that the student-teacher did not know that the tangent function has unlimited values. The use of an angle as the minimum value of the tangent function connotes a lack of understanding of the difference between the nature of elements of domains and ranges of trigonometric functions. It was not only failure by the student teachers to comprehensively explain the idea of extreme values in the context of the tangent function which was striking, but their inability to provide coherent justifications too. For example, one student teacher stated that the tangent function has no maximum value 'because this one will keep going up and up'. Instead of presenting a justification, the pre-service teacher attempted to describe a feature of tangent functions.

Based on the analysis of the collected data, it is obvious the majority of sampled student teachers of mathematics could not change the representation of a symbolic tangent function to its corresponding graphical representation. Only $5 \%$ of the initial sample demonstrated the ability to correctly sketch the graph of the tangent function in the domain $0^{\circ} \leq \theta \leq 360^{\circ}$. $45 \%$ of the pre-service teachers presented flawed graphs. For example, they drew graphs that gave a misleading impression that the tangent function is defined at $90^{\circ}$ and $270^{\circ}$. The wrong curve segments bearing a resemblance of the tangent graph as drawn by these teachers suggest that their understanding was a product of memorization of the appearance of a tangent graph. Thus, the pre-service teachers lacked understanding and ability to translate a symbolic tangent function to its graphical representation. $50 \%$ of the pre-service teachers did not present any graphs at all and likewise, this finding suggested the participants' complete inability to translate a symbolic tangent function to the graphical representation. Interview findings corroborated the foregoing picture in that the majority of the interviewees could not elucidate the flawed 
graphs. The interviewees also maintained during interviews that the tangent function is defined at $90^{\circ}$ as well as at $270^{\circ}$. This was although these pre-service teachers could not justify this view. The preceding scenario suggests that either the teachers lacked understanding concerning the discontinuity of the tangent function at the two angles and were merely guessing or that they had a superficial understanding of an incorrect perspective.

Furthermore, the pre-service teachers could not explain coherently the characteristics of the tangent curve in specific intervals of angles such as $0^{\circ}<\theta<90^{\circ}$, $90^{\circ}<\theta<180^{\circ}, 180^{\circ}<\theta<270^{\circ}$, and $270^{\circ}<\theta<360^{\circ}$ for the given domain. Likewise, they could not provide reasons to justify the features of the tangent curve at these intervals. These findings point to the fact that the student teachers lacked relational understanding (Skemp, 2006) concerning the angles at which the tangent function is continuous or discontinuous. This confirms the test finding that the student teachers who attempted to translate the tangent function had merely memorized its graphical appearance without the attainment of relational understanding. Of course, the teachers recognized the tangent function in symbolic form by word of mouth, but could not connect their understanding of the symbolic representation to the corresponding graphical representation. This disconnect suggests that the pre-service teachers' understanding of the tangent function was compartmentalized within representations (Gerson, 2010). Moreover, the failure of the student teachers to explain features composing a tangent function even when they could recognize the symbolic form of the function suggests that their understanding was compartmentalized within concepts (Gerson, 2010). An example of the teachers' understanding being compartmentalized within concepts relates to a case where they stated the correct period of the tangent function and yet their drawn graphs portrayed a lack of understanding of what they had indicated orally. In other words, the pre-service teachers' drawn graphs did not depict a period of $180^{\circ}$ for a tangent function.

The study also established that the student teachers lacked understanding of the centrality of a domain when defining a function. In this regard, student teachers drew graphs which went beyond the upper limit of the prescribed domain. Apart from that, student teachers had a misunderstanding that angles of a tangent curve can only be expressed in terms of $\pi$. This is consistent with findings of previous studies which established that students' concept images of angle measures are dominated by $\pi$ (Akkoc, 2008).

The implication of the discussion above is that while the pre-service teachers had studied advanced mathematics courses in the university, they had not acquired an in-depth understanding of the basic tangent function as taught in secondary school. Furthermore, despite being in the final phase of teacher training, the pre-service teachers did not have the mathematical knowledge necessary to comprehensively explain the tangent function and provide justifications for their reasoning. These findings, though limited to the tangent function, reinforce the view that pre-service mathematics teachers' study of higher mathematics in university does not inevitably enable them to understand school mathematics concepts (Malambo, 2016). A concern that arises relates to how pre-service teachers who have studied advanced mathematics but still lack a relational understanding of basic school mathematics concepts could assist learners to acquire a conceptual understanding of the same concepts. The situation where finalist pre-service mathematics teachers exhibit conceptual challenges with an understanding of the subject matter to be taught requires attention by relevant stakeholders. This is a valid perspective especially that it is generally accepted that teacher knowledge influences their teaching (Fennema \& 
Franke, 1992; Grouws \& Schultz, 1996). Research has also provided evidence of a significant relationship between teachers' content knowledge and pupils' achievement in specified mathematics sub-topics (Ogbonnaya \& Mogari, 2014). The existence of such a relationship is critical for African countries like Zambia where every year candidates continue to perform poorly in mathematics at Grade 12 national examinations level (Ministry of Education, 2013b). Regarding Zambia, it is reported that on a cumulative basis, one-third of boys, and two-thirds of girls who sat for Grade 12 national examinations registered complete fail in mathematics since 2005. Moreover, only half of the boys and one-fifth of the girls managed to obtain a pass or better (Ministry of Education, 2013b). Although about 5 years have passed since the preceding scenario was revealed, it can be stated here that performance levels of candidates in Grade 12 mathematics summative assessments are still similar (Examinations Council of Zambia, 2016). The failure of candidates in school mathematics examinations could be attributed to factors such as mathematics teachers' lack of an in-depth understanding of secondary school mathematics. Although mathematics teachers develop their subject matter knowledge from the wisdom of practice, it cannot be ignored that they also acquire their knowledge of mathematics concepts during their pre-service training. Consequently, what pre-service teachers study and how they are taught are significant matters requiring special consideration in teacher education.

\section{Conclusion}

This article set out to establish how pre-service mathematics teachers' ability to translate the tangent function between representations could be described. Equally, the intention was to explore the student teachers' explanations of ideas linked to the tangent function. Furthermore, the purpose was to acquire an understanding of the justifications which the pre-service mathematics teachers hold for their reasoning in the context of the tangent function. Regarding the first objective, it was discovered that $95 \%$ of the preservice mathematics teachers did not know how to change the representation of a tangent function from a symbolic form to the graphical form. Except for one teacher, all the other teachers who drew graphs demonstrated a lack of relational understanding of the tangent function and the significance of a domain of a function. Similarly, the teachers had not acquired the mathematical knowledge necessary for them to provide comprehensive explanations of the features of the tangent function. Furthermore, the study revealed that pre-service mathematics teachers were incapable of presenting coherent justifications for their viewpoints in the context of the tangent function. All in all, the pre-service mathematics teachers' nature of understanding of the tangent function was superficial.

There is, therefore, a compelling need to begin confronting seriously the question concerning the kind of mathematical subject matter student teachers should study during training and how they should study it. Because of this, it is necessary to propose that preservice mathematics teachers' study of advanced mathematics should be adequately supplemented with opportunities for exploration of school mathematics concepts. Besides, teacher education programs should not only focus on procedural knowledge but should enable trainee teachers to acquire abilities to coherently explain mathematics concepts and provide justifications for their reasoning.

\section{Acknowledgment}

The author wishes to extend profound gratitude to the university student teachers of mathematics who participated in the study upon which this article is based. 


\section{Bibliography}

Abdulkadir, T. (2013). A conceptual analysis of the knowledge of prospective mathematics teachers about degree and radian. World Journal of Education, 3(4), 1. Retrieved from https://files.eric.ed.gov

Akkoc, H. (2008). Pre-service mathematics teachers' concept images of radian. International Journal of Mathematical Education in Science \& Technology, 39(7), 857878. https://doi.org/10.1080/00207390802054458

Bair, S. L., \& Rich, B. S. (2011). Characterizing the Development of Specialized Mathematical Content Knowledge for Teaching in Algebraic Reasoning and Number Theory. Mathematical Thinking \& Learning, 13(4), 292-321. https://doi.org/10.1080/10986065.2011.608345

Ball, D. L., Thames, M. H., \& Phelps, G. (2008). Content Knowledge for Teaching: What Makes It Special? Journal of Teacher Education, 59(5), 389-407. https://doi.org/10.1177/0022487108324554

Bromme, R. (1994). Beyond subject matter: A psychological topology of teachers' professional knowledge. In R. Biehler, Scholz, W. R., StraBer, R., \&Winkelmann, B. (Ed.), Didactics of mathematics as a scientific discipline (pp. 73-88). The Netherlands: Kluwer Academic Publishers.

Cooney, T. J. \&Wiegel, H.G. (2003).Examining the mathematics in mathematics teacher education. In A. J. C. M. A. K. Bishop, C; Kilpatrick, J and Leung, F.K.S (Ed.), Second International Handbook of Mathematics Education (pp. 795). Netherlands: Kluwer Academic Publishers.

Creswell, J. W. (2012). Educational Research Planning, Conducting, and Evaluating Quantitative and Qualitative Research (Fourth ed.). United States of America: Pearson Education.

Creswell, J. W. (2014). Research design: Qualitative, quantitative and mixed methods approaches. Thousand Oaks, CA: Sage.

Examinations Council of Zambia (2016).2015 Examination Performance Review Report for Natural Sciences. Lusaka: Examination Council of Zambia.

Fennema, E., \&Franke, M. L. (1992).Teachers' knowledge and its impact.In D. A. Grouws (Ed.), Handbook of Research on Mathematics Teaching and Learning (pp. 147-164). New York: McMillan Publishing Company.

Gerson, H. (2010). David's Understanding of Functions and Periodicity.School Science and Mathematics.108(1), 28-38. Retrieved from https://www.researchgate.net

Grouws, D. \& Schultz, K. (1996). Mathematics Teacher Education: In Sikula, J. (Ed) Handbook of Research on Teacher Education, 2nd edition (USA: Macmillan).

Malambo, P. (2016). Exploring Zambian Mathematics Student teachers' content knowledge of functions and trigonometry for secondary schools (University of Pretoria).Retrieved from http://hdl.handle.net/2263/52943.

Malambo, P., van Putten, S., Botha, H., Stols, G. (2018). Mathematics Student Teachers' Understanding of Trigonometry for Secondary Schools. Nov 201811th annual International Conference of Education, Research and Innovation, Spain.Retrieved from https://library.iated.org.

Malambo, P., van Putten, S., Botha, H., Stols, G. (2019). Dysfunctional Functions: The Case of Zambian Mathematics Education Students. Eurasia Journal of Mathematics, Science and Technology Education, 15(1), em1651. https://doi.org/10.29333/ejmste/99510

Merriam, S. B. (2009). Qualitative Research A Guide to Design and Implementation (Second ed.). San Francisco, CA 94103-1741: Jossey-Bass. 
Ministry of Education. (2013a). "O" Level Mathematics Syllabus (Grades 10 to 12) Lusaka, Zambia.: Zambia Curriculum Development Centre.

Ministry of Education. (2013b). Zambia Education Curriculum Framework. Lusaka: Zambia Curriculum Development Centre.

Nyikahadzoyi, M. R. (2015). Teachers' Knowledge of the concept of a function: A theoretical framework. International Journal of Science and Mathematics Education, 13, 261-283. https://doi.org/10.1007/s10763-013-9486-9

Ogbonnaya, U. I., \& Mogari, D. (2014). The Relationship Between Grade 11 Students' Achievement in Trigonometric Functions and Their Teachers' Content Knowledge. Mediterranean Journal of Social Sciences, 5(4), 443. Retrieved from https://pdfs.semanticscholar.org

Shulman, L. (1986). Those whounderstand: Knowledge growth in teaching. Educational Researcher, 15(2), 4-14. Retrieved from www.jstor.org/stable/1175860

Skemp, R. (2006). Relational Understanding and Instrumental Understanding. Mathematics Teaching in the Middle School, 12(2), 88-95.

Steele, M. D., Hillen, A. F., \& Smith, M. S. (2013). Developing mathematical knowledge for teaching in a methods course: the case of function.Journal of Mathematics Teacher Education, 16(6), 451-482. https://doi.org/10.1007/s10857-013-9243-6 